\title{
New cellular players in Sjögren syndrome pathogenesis
}

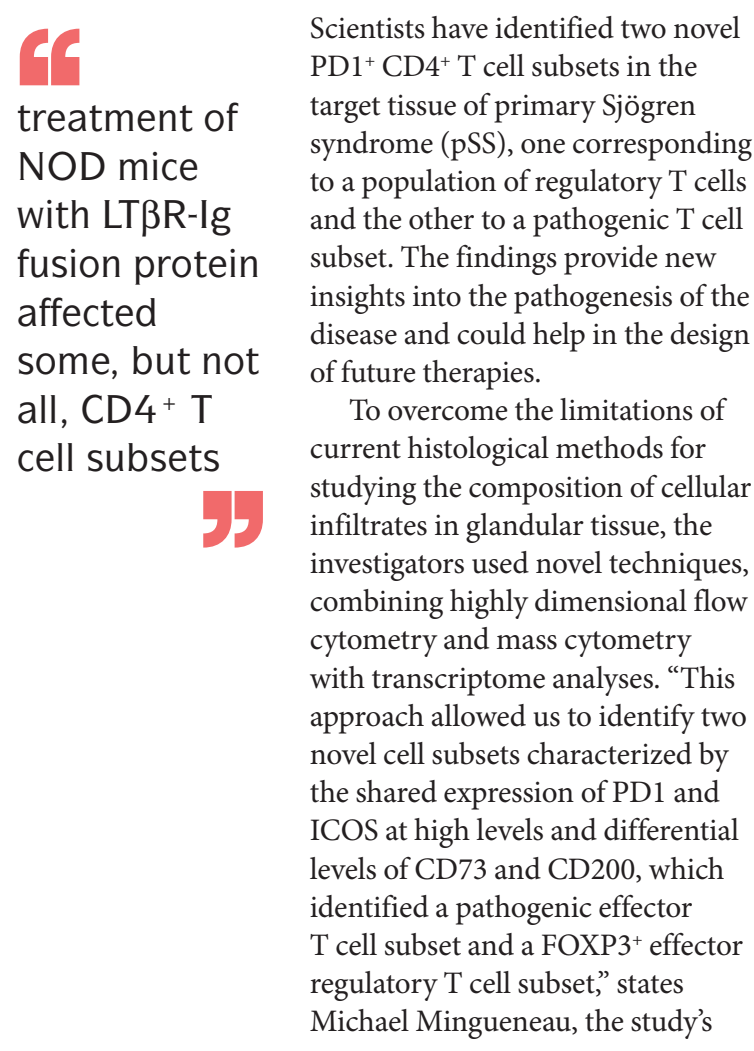

corresponding author. Initially identified in lacrimal gland tissue of NOD mice, the presence of these T cell subsets was also verified within salivary gland tissue of patients with pSS.

Mingueneau and colleagues next examined the effects of lymphotoxin- $\beta$ receptor-Ig (LT $\beta$ R-Ig) fusion protein treatment on the recruitment and accumulation of these cells. "A strong body of data gathered from mouse models supported the notion that treatment with LT $\beta$ R-Ig would prevent or reverse the hallmark inflammatory infiltrates in, and improve the function of, the target tissues of pSS, thereby alleviating disease symptoms," explains co-author Taylor Reynolds. However, treatment of NOD mice with LT $\beta$ R-Ig fusion protein affected some, but not all, $\mathrm{CD}^{+} \mathrm{T}$ cell subsets, an observation that could explain why a clinical trial of the LT $\beta$ R-Ig fusion protein baminercept did not meet its primary end point. "Importantly, unlike naive
$\mathrm{CD} 4^{+} \mathrm{T}$ cells, recruitment of $\mathrm{PD} 1^{+}$ effector $\mathrm{T}$ cells to the target tissue in NOD mice was not halted by treatment with LT $\beta$ R-Ig, a finding which, if also true in humans, could contribute to the lack of clinical benefit in pSS patients in the baminercept trial," Reynolds says.

These findings could help "pave the way to the development of improved therapeutic strategies that would selectively affect the cell subsets with pathogenic potential while leaving unaffected cells with immunoregulatory functions," concludes Mingueneau.

Jessica McHugh

ORIGINAL ARTICLE Haskett, S. et al. Identification of novel $C D 4^{+} T$ cell subsets in the target tissue of Sjögren's syndrome and their differential regulation by the lymphotoxin/LIGHT signaling axis. J. Immunol. http://dx.doi. org/10.4049/jimmunol.1600407 (2016). FURTHER READING St Clair, E. W. et al. The clinical efficacy and safety of baminercept, a lymphotoxin- $\beta$ receptor fusion protein, in primary Sjögren's syndrome: results from a randomized, double-blind, placebo-controlled phase II trial [abstract]. Arthritis Rheumatol. 67 (Suppl. 10), 3203 (2015). 